\title{
Precision Electroweak Measurements at Future High Energy Colliders
}

\author{
Alain Blondel* \\ Dép. de Physique Nucléaire et Corpusculaire, University of Geneva \\ E-mail: alain.blondel@cern.ch
}

The prospects for precision measurements of the properties of the Z, W, Higgs and top particles will be reviewed. The machines considered will be the LHC and its upgrade, the future e+ecolliders, both linear and circular, and the $100 \mathrm{TeV}$ Future Hadron Collider. The importance of improvements in some other experimental inputs and in the theoretical calculations will be addressed.

Frontiers of Fundamental Physics 14 - FFP14,

15-18 July 2014

Aix Marseille University (AMU) Saint-Charles Campus, Marseille

${ }^{*}$ Speaker. 